\title{
PEMBERDAYAAN PETUGAS KESEHATAN DAN KADER PUSKESMAS DALAM PENGELOLAAN LIMBAH RUMAH TANGGA SEBAGAI KOMPOS
}

\section{Empowerment Of Health Officer And Health Center Cadre In Management Of Household Waste As Compost}

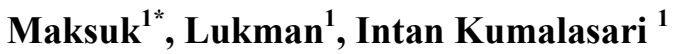 \\ ${ }^{1}$ Politeknik Kesehatan Kemenkes Palembang \\ maksuk@poltekkespalembang.ac.id
}

\begin{abstract}
ABSTRAK
Petugas kesehatan dan kader puskesmas mempunyai peran penting dalam mengelola limbah rumah tangga di masyarakat, karena itu peningkatan keterampilan untuk mengelola limbah tersebut penting dilakukan agar limbah tersebut dapat dimanfaatkan dan menguntungkan. Metode pengelolaan limbah rumah tangga menggunakan konsep Pilah - Kumpul - Manfaat - Untung (PKMU) untuk mengurangi volume sampah rumah tangga dan menguntungkan masyarakat. Peserta yang terlibat dalam kegiatan ini terdiri dari petugas kesehatan, kader puskesmas dan masyarakat yang berasal dari di RT 14 dan RT 33. Target capaian dalam kegiatan ini adalah peningkatan kemampuan petugas kesehatan dan kader dalam mengelola limbah rumah tangga, pemanfaatan limbah rumah tangga untuk media penanaman tanaman obat, keluarga serta pembentukan kelompok kerja asuhan mandiri kegiatan batra di puskesmas dan pembentukan pengelola bank sampah. Hasil dari kegiatan ini menunjukkan bahwa kader dan masyarakat dapat memanfaatkan sampah rumah tangga sebagai membuat kompos. Selain itu limbah rumah tangga seperti plastik dapat dimanfaatkan kembali. Tindak lanjut dari kegiatan ini yaitu terbentuknya pengelola bank sampah di lokasi kegiatan.
\end{abstract}

Kata Kunci : Pemberdayaan, Petugas Kesehatan, Kader, Pengelolaan Limbah Rumah Tangga

ABSTRACT

Health officers and cadre at public health center have an important role in managing of households in the community, therefore it is important to improve skills to manage such waste so that the waste can be utilized and beneficial. The method of managing household waste in this activity uses the concept of Pilah - Kumpul Manfaat - Untung (PKMU) to reduce the volume of household waste and provide benefits to the community. Participants involved in this activity were health workers, kader of community health centers and the community of RT 14 and RT 33. The Achievement targets in this activity were to improve the ability of health workers and cadres to manage of household waste, use of household waste for the planting of medicinal plants, families and the formation of independent care working groups for batra activities in health center and the formation of waste bank managers. The results of this activity show that cadres and the community can use household waste as compost, in addition, household waste such as plastic can be reused. The follow up of this activity is the formation of a waste bank manager at the location of the activity.

Keywords : Empowerment, Health Officers, Cadre, Management of Household Waste

\section{PENDAHULUAN}

$$
\text { Sampah rumah tangga }
$$

merupakan sisa-sisa dari kegiatan sehari-hari yang dihasilkan masyarakat termasuk didalamnya sisa-sisa bahan yang tidak dimanfaatkan atau dibuang. Kondisi ini lama kelamaan dapat meningkatkan jenis dan volume sampah sehingga dapat mencemari lingkungan dan menyebabkan berbagai masalah terutama masalah kesehatan bagi masyarakat. Permasalahan sampah sampai saat ini menjadi masalah yang belum dapat diatasi secara optimal dan masih perlu dilakukan pengelolaan terutama sampah yang dihasilkan dari rumah tangga.

Pengelolaan sampah yang belum optimal dilakukan oleh masyarakat dan pemerintah daerah dapat mempengaruhi lingkungan dan kesehatan masyarakat sekitarnya serta menyebabkan kerugian, diantaranya: menimbulkan bau busuk, mengganggu keindahan, menyebabkan banjir, meningkatnya pemanasan iklim, memperburuk sanitasi lingkungan dan ancaman 
meningkatnya berbagai macam penyakit (Yudistirani, 2015).

Sampah yang tidak dikelola dengan baik berkontribusi terhadap keindahan lingkungan, pencemaran udara dan berdampak terhadap gangguan kesehatan masyarakat diantaranya penyakit pernafasan, diare, demam berdarah dan penyakit menular lainnya (World Bank, 2012). Oleh karena itu masyarakat sebagai sumber penghasilkan sampah pada level rumah tangga harus diberdayakan dan dilibatkan secara aktif dalam pengelolaan sampah.

Masalah sampah di Indonesia termasuk Kota Palembang merupakan masalah yang sulit diatasi karena kurangnya kesadaran, kepedulian dan partisipasi masyarakat untuk memelihara kebersihan serta memilah sampah sebelum dibuang. Peningkatan volume sampah di perkotaan termasuk Kota Palembang berbanding lurus dengan pertambahan jumlah penduduk. Jumlah penduduk Kota Palembang sampai saat ini sekitar 1.643.488 jiwa, dengan jumlah penduduk yang mencapai 1,6 juta jiwa tentunya akan menyumbangkan berbagai jenis sampah terutama yang berasal dari rumah tangga(BPS Kota Palembang, 2019).

Setiap harinya volume sampah yang dihasilkan di Kota Palembang kurang lebih 700 ton/hari dan setiap orang dapat menghasilkan sampah di kota besar termasuk Palembang sekitar 0,5 kg/orang/hari. (DKK Palembang, 2016). Pengelolaan sampah di Kota Palembang masih bertumpu pada pendekatan akhir (end of pipe) yaitu sampah dikumpulkan, diangkut dan dibuang ke tempat pembuangan akhir (TPA). Salah satu Tempat Pembuangan Akhir (TPA) sampah di Kota Palembang yaitu TPA Sukawinatan yang beroperasi sejak tahun 1994 dengan luas lahan 25 hektar telah terpakai 15 hektar, dan sisa lahan 10 hektar diperkirakan dapat menampung sampah hingga tahun 2017 (DKK Palembang, 2016).

Oleh karena itu pengelolaan sampah dapat lebih optimal jika ada kerjasama antara petugas kesehatan, kader puskesmas, masyarakat dan pemerintah setempat. Melalui keterlibatan masyarakat tersebut, maka mereka lebih mempercayai program pembangunan jika dilibatkan dalam suatu kegiatan dari mulai proses persiapan dan perencanaan serta sampai tahap pelaksanaan (Maulina, 2012).

Berdasarkan hasil survei pendahuluan yang dilakukan sebelum kegiatan pengabdian masyarakat ini dilakukan diperoleh gambaran bahwa sampah di wilayah kerja Puskesmas Satu Ulu tertumpuk dimana - mana dan pada saat musim hujan sampah terbawa aliran air ke sungai. Melalui pendekatan pengelolaan sampah rumah tangga berbasis masyarakat dengan melibatkan unsur pemerintah, petugas kesehatan, kader dan masyarakat diharapkan diperoleh solusi inovatif untuk membiasakan masyarakat dalam mengelola sampah sejak dari level rumah tangga.

Oleh karena itu perlu dilakukan pengelolaan sampah secara terintegrasi berbasis masyarakat dengan berkolaborasi dengan pemerintah, petugas kesehatan dan kader sebagai fasilitator di wilayah kerjanya. Pendekatan pengelolaan sampah yang didasarkan pada kebutuhan masyarakat, direncanakan, dilaksanakan, dikendalikan dan dievaluasi bersama masyarakat dapat mengurangi volume sampah yang berasal dari rumah tangga (Sidik, 2009). Sistem penanganan sampah yang direncanakan, disusun, dioperasikan, dikelola dan dimiliki oleh masyarakat (Yuwono dkk, 2008).

Permasalahan pada kelompok sasaran (mitra) yaitu masalah sampah rumah tangga yang semakin meningkat dan belum diolah secara optimal. Selain itu kurangnya informasi dan kesadaran masyarakat untuk memanfaatkan kembali sisa - sisa sampah rumah tangga yang mereka hasilkan.

Target kegiatan ini sebagai berikut:

1. Pengelolaan sampah rumah tangga bersama - sama kader dan petugas puskesmas dengan menanam tanaman obat keluarga dengan memanfaatkan sampah plastik.

2. Membuat kompos dari sisa sayuran dan sampah organik lainnya sebagai pupuk untuk tanaman obat keluarga.

3. Persiapan pembentukan pengelola bank sampah di Wilayah Kerja Puskesmas Satu Ulu Kota Palembang.

Adapun luaran kegiatan yaitu:

1. Meningkatkan pengetahuan dan ketrampilan kader, petugas kesehatan dan 
masyarakat dalam pengelolaan sampah rumah tangga

2. Sosialisasi dan demonstrasi pembuatan kompos menggunakan sisa-sisa sayur dan buah.

3. Terbentuknya pengelola bank sampah di Wilayah Kerja Puskesmas Satu Ulu

\section{METODE}

Metode pelaksanaan menjelaskan rancangan metode kegiatan yang akan dilaksanakan, dalam hal ini dapat digunakan Adapun 3 kegiatan tersebut yaitu:

1. Sosialisasi pemilahan sampah pada level rumah tangga dan memanfaatkan kembali sampah

2. Pembuatan kompos dari sisa - sisa sayur atau sampah organik lainnya untuk penanaman tanaman obat keluarga.

3. Pembentukan pengelola bank sampah di wilayah kerja Puskesmas Satu Ulu Kota Palembang.

\section{HASIL DAN PEMBAHASAN}

Masalah persampahan merupakan masalah yang secara klasik belum dapat ditangani secara optimal termasuk di wilayah kerja Puskesmas Satu Ulu Kota Palembang. Kondisi ini dapat dilihat dari pada gambar dibawah ini:

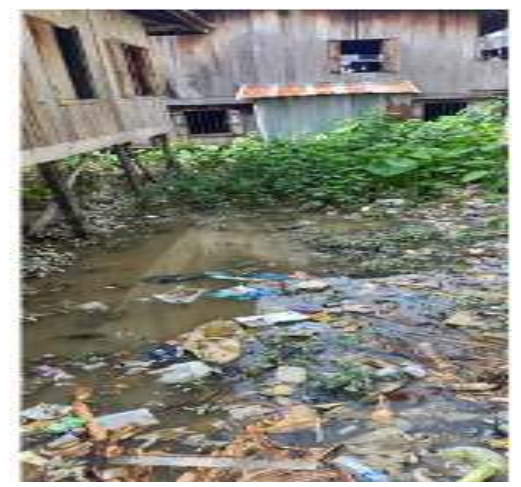

Gambar 1. Tumpukan Sampah di Lokasi Kegiatan

Di wilayah kerja Puskesmas Satu Ulu Kota Palembang pengelolaan sampah pada tatanan rumah tangga belum optimal dilakukan. Hal ini dibuktikan pada Gambar 1 tumpukan sampah masih banyak ditemukan di sekitar rumah masyarakat.

Pengelolaan limbah rumah tangga di Kota Palembang sampai saat ini masih mengikuti paradigma lama yaitu pengangkutan dan pembuangan akhir atau masih bertumpu pada pendekatan akhir (end of pipe) yaitu sampah dikumpulkan, diangkut dan dibuang ke tempat pembuangan akhir (TPA) termasuk di wilayah kerja Puskesmas Satu Ulu Kota Palembang. Kondisi ini disebabkan oleh keterbatasan lahan untuk TPA sudah saatnya pemerintah daerah mengubah pola pikir yang lebih berwawasan lingkungan. Konsep pengelolaan sampah yang terpadu sudah saatnya diterapkan, yaitu dengan mengurangi volume sampah terutama plastik dan maksimalkan pengelolaan limbah pada level rumah tangga.

Sesuai dengan amanat Undang-Undang Nomor 18 Tahun 2008 tentang Pengelolaan Sampah dan Peraturan Pemerintah Nomor 81 Tahun 2012 perlu perubahan paradigma yang mendasar dalam pengelolaan sampah yaitu dari paradigma kumpul- angkut-buang, menjadi pengolahan yang bertumpu pada pengurangan sampah dan penanganan sampah. Paradigma pengelolaan sampah yang bertumpu pada pendekatan akhir seharusnya sudah saatnya ditinggalkan dan diganti dengan paradigma baru dengan cara memanfaatkan sampah sehingga mempunyai nilai ekonomis dan dapat dimanfaatkan, diantaranya untuk kompos dan pupuk terutama pada tatanan rumah tangga.

Proses pemanfaatan sisa - sisa sayuran atau bahan organik lainnya sebagai bahan baku pembuatan kompos dapat mengurangi pencemaran lingkungan (Murbanono, 2002). Produk hasil pengomposan bermanfaat bagi tanah dan tanaman, dan dapat dimanfaatkan untuk pupuk tanaman obat keluarga atau tanaman lainnya. Oleh karena itu berdasarkan hal tersebut dalam kegiatan ini telah dilakukan simulasi pembuatan kompos sederhana yang selanjutnya dapat dilakukan sendiri oleh masyarakat di lingkungan RT 14 dan RT 33 wilayah kerja Puskesmas Satu Ulu Kota Palembang.

Agar sampah dapat memberikan nilai ekonomis dan keuntungan bagi masyarakat maka melalui kegiatan pengabdian masyarakat ini dilakukan pembentukan pengelola bank sampah di wilayah kerja Puskesmas Satu Ulu Kota Palembang yang secara jangka panjang akan dikelola oleh masyarakat sendiri. Adapun kegiatan simulasi pemilahan sampah dan 
pembuatan kompos menggunakan limbah rumah tangga dapat dilihat pada gambar dibawah ini:

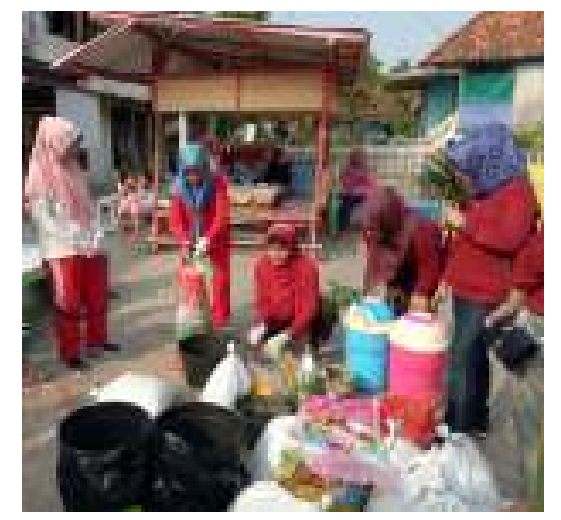

Gambar 1. Simulasi pembuatan kompos

Bank Sampah adalah tempat menabung sampah yang telah terpilah menurut jenis sampah (Aryeti, 2011). Bank Sampah dalam pelaksanaanya dapat mengurangi volume sampah di masyarakat dan di tempat pembuangan akhir (TPA). Pengelolaan sampah tidak hanya Bank Sampah, tetapi juga bisa melalui Sodaqoh Sampah dengan harapan agar semangat solidaritas, kebersamaan, handarbeni (rasa saling memiliki) tetap kuat dan berakar di dalam masyarakat (Perdana dkk, 2016).

Pengelolaan Bank Sampah juga mengikuti kaidah-kaidah yang terdapat dalam Undangundang Nomor 18 Tahun 2008 tentang Pengelolaan Sampah dengan prinsip 3R. Oleh karena itu sebagai target capaian jangka panjang dalam kegiatan pengabdian kepada masyarakat ini adalah terbentuknya pengelolaan sampah melalui Bank Sampah di wilayah kerja Puskesmas Satu Ulu Kota Palembang. Dalam pengelolaan sampah rumah tangga peran serta masyarakat sangat besar pengaruhnya untuk keberhasilan program pengelolaan sampah berbasis masyarakat (Artiningsi, 2008;Sidiq, 2009).

Oleh karena itu solusi pemecahan yang ditawarkan penulis dalam mengatasi persampahan yang ada tepatnya di wilayah kerja Puskesmas 1 Ulu Kota Palembang menggunakan metode pendekatan dengan paradigma Pilah-Kumpul-Manfaat-Untung (PKMU). Melalui metode ini sampah sudah mulai dilakukan pemilahan pada level rumah tangga sehingga cara ini membantu mengurangi volume sampah terutama plastik yang tidak mudah terurai di lingkungan.

\section{KESIMPULAN}

Pengelolaan sampah merupakan kegiatan yang harus dimulai dari rumah tangga dalam mengurangi volume sampah dan pemanfaatan kembali sisa - sisa sayuran, buah dan bahan organik lainnya untuk kompos. Metode Pilah Kumpul - Manfaat - Untung (PKMU) merupakan solusi yang ditawarkan untuk membantu mengurangi volume sampah dan daur ulang sampah sehingga dapat digunakan oleh masyarakat sebagai pupuk atau kompos sebagai media penanaman tanaman obat keluarga. Kegiatan ini dapat menguntungkan masyarakat yaitu melalui pembentukan pengelola bank sampah yang dikelola oleh masyarakat sendiri, sehingga hasinya dapat dinikmati oleh masyarakat.

Untuk keberlanjutan program maka pengelolaan sampah dilakukan dengan pembentukan pengelola Bank Sampah sebagai salah satu alternatif solusi bagi pemerintah dan masyarakat untuk mengurangi peningkatan volume sampah yang semakin tidak terkendali. Selain memberikan dampak positif bagi lingkungan, dalam proses pengelolaannya, bank sampah memiliki mekanisme relasi dan jaringan sosial yang bernilai ekonomis.

Rekomendasi dari hasil kegiatan pengabmas ini adalah:

1. Perlu adanya kerjasama yang baik antara dosen, aparat pemerintah dan masyarakat setempat agar kegiatan pengelolaan sampah rumah tangga dapat berjalan dengan baik dan berelanjuta.

2. Dalam rangka pengembangan bank sampah ke depan pemerintah perlu memfasilitasi dalam bentuk sosialisasi, pemberian dana hibah atau pinjaman modal, dan pelibatan pihak swasta, melalui Corporate Social Responsibility (CSR), untuk membantu pengembangan Bank Sampah.

\section{DAFTAR PUSTAKA}

Artiningsih Ni Komang Ayu (2008). Peran Serta Masyarakat dalam Pengelolaan Sampah Rumah Tangga (Studi kasus di Sampangan dan Jomblang, Kota Semarang). Semarang: Tesis, UNDIP. 
Aryeti. (2011). Peningkatan Peran serta Masyarakat Melalui Gerakan Menabung pada Bank Sampah di Kelurahan Babakan Surabaya, Kiaracondong Bandung. Jurnal Permukiman. 6 (1):40-46.

Badan Pusat Statistik Kota Palembang, (2019). Jumlah Penduduk Kota Palembang Tahun 2009 2018. https://palembangkota.bps.go.id/dynamict able/2019/12/09/104/jumlah-pendudukkota-palembang-tahun-2009-2018.html

Dinas Kebersihan Kota Palembang, (2016). Profil Dinas Kebersihan Kota Palembang.

Maulina, AS, (2012). Identifikasi Partisipasi Masyarakat Dalam Pemilahan Sampah di Kecamatan Cimahi Utara Serta Faktor Yang Mempengaruhinya. Jurnal Perencanaan Wilayah dan Kota. 23 (3): $177-196$.

Murbanono, HSL. (2002). Membuat Kompos. Penerbit Penebar Swadaya. Jakarta.
Perdana, HD, Hananto, TS, Bandi, Murni S, (2016). Peningkatan Sarana Prasarana Pengelolaan Sampah Rumah Tangga Desa Doplang Kabupaten Boyolali, JPKM, 22(4): 1-9.

Sidik, US. (2009). Implementasi Peran Masyarakat Sesuai UU NO. 18 Tahun 2008. Majalah Percik Bulan Mei, Edisi Khusus Pengelolaan Sampah Berbasis Masyarakat, Pokja AMPL, Jakarta.

Undang-Undang No. 18 Tahun 2008 tentang Pengelolaan Sampah.

Yudistirani, SA, Syaufina, L., Mulatsih, S. (2015). Desain Sistem Pengelolaan Sampah Melalui Pemilahan Sampah Organik dan Anorganik Berdasarkan Persepsi Ibu-ibu Rumah Tangga. Konversi. 4 (2):29-42.

Yuwono, RL. Wardhani, U, Ninghadiyati, Adinugroho, E. (2008). Pengembangan Sistem Persampahan Berbasis Masyarakat. Pokja AMPL, Jakarta. 